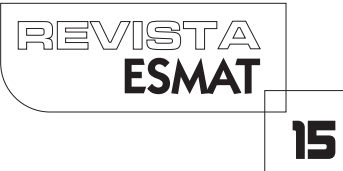

\section{BREVES REFLEXÕES SOBRE SIMONE WEIL, A ESCOLA DA PONTE E O ENSINO JURÍDICO}

\author{
BRIEF REFLECTIONS ON SIMONE WEIL, BRIDGE SCHOOL AND LEGAL EDUCATION
}

André Peixoto de Souza

Doutor em Direito pela UFPR e Doutor em Educação pela UNICAMP. Professor do PPGDUNINTER.

Marta Savi

Mestranda do PPGD-UNINTER.

\section{RESUMO}

presente artigo apresenta algumas reflexões sobre o pensamento da filósofa francesa Simone Weil (1909-1943), reunido postumamente em A Condição Operária e Outros Estudos Sobre a Opressão. Grande parte da obra estudada foi construída pela autora durante os anos de 1935 e 1937, período em que trabalhou como operária em fábricas na França -, por meio de anotações em diários e envio de cartas, além da transcrição parcial de discursos e escritos para jornais. Busca-se, com este estudo, entender de que forma o conteúdo produzido pela filósofa pode ser aplicado na transformação do ensino jurídico do país, combinando a reflexão, ainda, com as propostas educacionais defendidas pela Escola da Ponte, em Portugal.

PALAVRAS-CHAVE: Simone Weil; Escola da Ponte; Ensino Jurídico.

\begin{abstract}
This article presents some reflections on the thinking of the french philosopher Simone Weil (1909-1943), posthumously gathered in The Working Condition and Other Studies on Oppression. Grade part of the work studied was constructed by the author during the years of 1935 and 1937, during which time she worked as a factory worker in France through notes in diaries and letters, as well as the partial transcription of speeches and writings to newspapers. The aim of this study is to understand how the content produced by the philosopher can be applied in the transformation of the country's legal education, combining reflection with the educational proposals defended by the School of Bridge in Portugal.
\end{abstract}

KEYWORDS: Simone Weil; School of Bridge; Legal Education. 


\section{INTRODUÇÃO}

A segunda edição do livro A Condição Operária e Outros Estudos sobre a Opressão, que reúne textos da filósofa francesa Simone Weil selecionados e organizados por Ecléa Bosi', não divide apenas o ano de lançamento - 1996 - com a canção Capitão de Indústria, interpretada pela banda Os Paralamas do Sucesso no disco Nove Luas, que conta a história da rotina de um operário de fábrica que corre, dorme e acorda para trabalhar (VALLE; VALLE, 1996).

Mas, para que a comparação não pareça simplória ou descontextualizada, é preciso responder a alguns questionamentos que podem surgir dessas primeiras linhas. $\bigcirc$ primeiro - e talvez o mais importante deles - é sobre a autora dos textos contundentes que formam o compilado em questão, Simone Weil.

\section{ENTREAFONTEE OMANUAL: QUEM FOI SIMONE WEIL}

Nascida em 1909 e prematuramente falecida em 1943, Simone Weil foi uma figura peculiar por ter orbitado por diversas áreas de conhecimento e de atuação, dentre as quais destacam-se a docência e o trabalho como operária em fábricas, além da sempre presente militância de esquerda, com participação nas resistências espanhola, durante a Guerra Civil naquele país, e francesa na Inglaterra, durante a Segunda Guerra Mundial (BOSI apudWEIL, 1996, p. 21-73).

Contudo, apesar da biografia notável e de diversos escritos importantes e incisivos em vários campos, Simone é pouco debatida e explorada. Nem todas as suas obras compilados de registros em diários, cartas e textos publicados - possuem tradução para o português, e a produção acadêmica sobre seus escritos é pouca.

Não se pode negar que as décadas de 1930 e 1940 na Europa, anos de confecção dos textos da filósofa, são consideradas verdadeiras vedetes da História, dada a quantidade de material - acadêmico, ficcional, artístico, documental e autoral, para citar alguns exemplos - produzido sobre esse período em todos os tipos de mídia disponíveis, o que certamente solidifica um imaginário farto. Simone Weil, portanto, viveu, trabalhou e produziu suas reflexões em um curto, mas efervescente tempo histórico. Assim, é possível olhar para seus registros e também encará-los como retratos de uma época, como verdadeiras fontes.

' Graduada em Psicologia, pela Universidade de São Paulo (1966); mestra em Psicologia Social, pela Universidade de São Paulo (1970); doutora em Psicologia Social, pela Universidade de São Paulo (197I ). Professora emérita da Universidade de São Paulo. Currículo Lattes disponível em: <http://buscatextual.cnpq.br/buscatextual/visualizacv.do?id=K4787935T0> 
Dessa forma, para a construção do contexto aqui proposto, além dos textos de Weil, seleciona-se, dentre todo o rico material desenvolvido sobre o recente e marcante recorte, o suporte teórico do historiador Eric Hobsbawm, em seu já clássico A Era dos Extremos, capaz de conceder um olhar panorâmico (HOBSBAWM, 1995, p. | | -26), mas não superficial. Como qualquer manual, contudo, a obra de Hobsbawm é recheada de generalizações, omissões e opiniões pessoais de seu autor, que, entretanto, apresenta essa ressalva de forma imediata. Evidenciado de imediato este aspecto, podem-se destacar alguns pontos relevantes.

$\bigcirc$ primeiro deles é oriundo de uma constatação, em certa medida óbvia, do historiador: no século $X X$, só existiu paz até 19|4, ano em de eclosão da Primeira Guerra Mundial e propositalmente escolhido como início de seu século por Hobsbawm. É impossível, afirma, compreender esse século sem compreender as guerras que envolveram todas as grandes potências mundiais.

Assim, uma elementar anotação a ser feita é a contribuição desses conflitos de escala mundial para o desenvolvimento tecnológico da indústria bélica. Além, é preciso destacar o inegável laço constituído entre política e economia, demonstrado pela rivalidade política modelada a partir das competições econômicas (HOBSBAWM, 1995, p. 29-60). Contudo, a despeito das contribuições e dos avanços passíveis de verificação, para Hobsbawm:

A Primeira Guerra Mundial não resolveu nada. As esperanças que gerou - de um mundo pacífico e democrático de Estadosnação sob a Liga das Nações; de um retorno à economia mundial de 1913; mesmo (entre os que saudaram a Revolução Russa) de capitalismo mundial derrubado dentro de anos ou meses por um levante de oprimidos - logo foram frustradas. $\bigcirc$ passado estava fora de alcance, o futuro fora adiado, o presente era amargo, a não ser por uns poucos anos passageiros em meados da década de 1920. (HOBSBAWM, 1995, p. 59)

Na menina Simone, então com 10 anos, contudo, o fim da Guerra - que ainda não tinha ganhado alcunha de Primeira - e a assinatura do Tratado de Versalhes, em 1919, despertam inusitado sentimento de vergonha e "seu patriotismo de criança cede lugar à simpatia pelos vencidos" (BOSI apud WEIL, 1996, p. 23), uma marca que será evidenciada na construção de toda a sua personalidade e, por consequência, em toda a sua produção. Ecléa Bosi narra algumas situações peculiares da breve vida da filósofa as quais são capazes de demonstrar um vislumbre dessas motivações de Simone, das quais se pode destacar esta passagem:

Quando sua amiga Hélène Honnorat, vendo que ela empregava os anos da juventude nos mais duros trabalhos, perguntou:

- Mas afinal, Simone, por que faz isso, com aquilo que traz em 
você, com aquilo que você tem a dizer? - ela responde:

- Há coisas que eu não teria podido dizer se eu não tivesse feito isso. (BOSI apud WEIL, 1996, p. 64)

Apesar de a Primeira Guerra carregar consigo o signo de ser a "guerra para acabar com todas as guerras", um segundo conflito pareceu inevitável desde o fim do primeiro. Era evidente que a Alemanha, primordialmente, buscaria uma reação, era questão de tempo e, também, de quem tomaria a frente. As duas questões podem ser respondidas com apenas um nome, como bem observou Hobsbawm: Adolf Hitler. $\bigcirc$ Tratado de Versalhes, afinal de contas, havia deixado cicatrizes profundas também no orgulho alemão.

Neste ponto, vale destacar que este cenário de iminência de conflito foi - com uma acuidade quase profética - descrito por Simone Weil, em 1932, quando escreveu sobre "as Condições de uma Revolução Alemã" (WEIL, 1996, p. 185-191) e suas "primeiras impressões da Alemanha” (WEIL, 1996, p. 193- 195). Analisando com sobriedade o país germânico pela lente de reflexões de Leon Trotsky, diz que:

Trata-se, na verdade, menos da Alemanha do que da situação mundial estudada através da Alemanha. A pergunta que o mundo atualmente se faz, a pergunta que a crise atual da economia capitalista faz, é, aos olhos de Trotsky, a seguinte: fascismo ou revolução? A fase atual do regime capitalista - a maioria dos estudos dos economistas burgueses tendem para essa conclusão - não é mais compatível nem com o liberalismo econômico, nem, consequentemente, com a democracia burguesa. (...) A Alemanha, rodeada pelas nações que a venceram em 1918, privada de colônias, de economia desorganizada, de um lado pelas reparações, de outro lado sobrecarregada com a maquinaria industrial monstruosa que se propiciou - e da qual uma grande parte nunca funcionou -, é o país onde a crise está mais aguda. Não é, portanto, de se estranhar que o problema fascismo ou revolução ainda seja um problema só da Alemanha. Mas, a se acreditar em Trotsky, a Alemanha está destinada a resolver esse problema para o mundo inteiro. (WEIL, 1996, p. 185- I86)

Um mês depois, afirma que naquele país o clima político é estranhamente mais tranquilo do que em Paris, mas que "a ideologia nazista é espantosamente contagiante, especialmente no partido comunista (...) [e que] os operários alemães não estão, de forma alguma, dispostos a capitular, mas são sim incapazes de lutar" (WEIL, I996, p. 194).

Hobsbawm, por seu turno, também apresenta o colapso econômico do período entreguerras como de capital importância. Foi entre os anos de 1918 e 1939 que a economia capitalista sofreu abalos tão profundos que seu desmoronamento parecia 
inevitável. Ninguém parecia ter uma solução cabível para superar a crise instaurada. A Grande Depressão vivida depois do boom econômico dos anos de 1920 estagnou a economia e fez com que cada Estado fizesse o possível para proteger a própria economia de maiores danos. Dentro do trauma, ainda era possível destacar um ponto que, certamente, incomodava a todos os capitalistas: a URSS ${ }^{2}$ parecia estar imune ao colapso e se industrializava rapidamente, abandonando o atraso em que se encontrava antes da Primeira Guerra Mundial.

Era a falência de um modelo liberal de emprego do capital, juntamente com a vinda à tona, nos territórios coloniais, de um sentimento anti-imperialista. Aqui, pode-se destacar outra amostra da sensibilidade de Simone Weil que, em março de 1937, ao comentar um episódio sanguinário ocorrido na Tunísia que havia ganhado, finalmente, o noticiário na França, escreve:

No fundo, nós - e, quando digo nós, incluo a todos os que aderem a uma organização de União Popular -, nós somos exatamente iguais aos burgueses. Um patrão é capaz de condenar seus operários à mais atroz miséria e comover-se com um mendigo que encontra no seu caminho; e nós, que nos unimos em nome da luta contra a miséria e a opressão, ficamos indiferentes ao destino desumano que, longe, sofrem milhões de homens que dependem do governo de nosso país. (...) Agora correu sangue. A tragédia colonial acabou por tomar forma de notícia, a única acessível à nossa sensibilidade e à nossa inteligência rudimentares. (...) Quando imagino uma eventual guerra, misturam-se, eu reconheço, ao medo e ao horror que me causa tal perspectiva, um pensamento algo reconfortante. É que uma guerra europeia poderia servir de sinal para a grande desforra dos povos coloniais para castigar nossa despreocupação, nossa indiferença e nossa crueldade.

(WEIL, 1996, p. 222-224)

\footnotetext{
${ }^{2}$ A Revolução de 1917, criadora da União das Repúblicas Socialistas Soviéticas, a URSS, também é um marco de relevância para o século XX. Esse novo bloco declarou-se, por boa parte do século, como um sistema superior ao capitalismo e, historicamente, destinado ao triunfo sobre o modelo seguido pelo ocidente. Depois de Outubro de 1917, um novo quadro político se apresenta: é a revolução social em combate com a velha ordem. A Revolução Russa inspirou diversos movimentos de esquerda durante todo o século, ainda que tenha sofrido reveses inesperados de seu estabelecimento até sua ruína. O alcance mundial pretendido por Lênin não foi possível, mas é inegável que a Revolução teve influência nos processos de emancipação colonial, de descolonização e de contrarrevoluções frente à política social democrata europeia. A Revolução Russa, portanto, foi duplamente importante para o próprio capitalismo: salvando-o com sua campanha decisiva na $2^{\text {a }}$ Guerra Mundial e forçando-o a procurar soluções inovadoras durante todo o século. (HOBSBAWM, 1995. Páginas 6 |-89).
} 
Como se pode notar, a leitura de Simone Weil nos apresenta uma dinâmica um pouco diferente daquela esmiuçada de forma didática, geral e, talvez, burocrática por Hobsbawm. É possível comparar as duas narrativas invocando uma cena marcante de um dos filmes mais importantes do século XX: Titanic ( 1997).

A bordo do navio que estuda os destroços submersos do transatlântico que dá nome à película, a tripulação apresenta à sobrevivente Rose (Gloria Stuart), já idosa, uma animação feita em gráficos simples por computador que reproduz os eventos que levaram ao naufrágio, ocorrido em abril de 1912. Após a fria, não emocional e técnica narrativa do capitão, feita em sincronia com as imagens, a personagem sorri e diz: "obrigada pela boa análise forense, Sr. Bodine. É claro, a experiência real foi... um pouco diferente" ${ }^{3}$.

É dentro deste contexto - desta trama, para aplicar o conceito de Paul Veyne (VEYNE, 1998, p. 42) - que, em 1934, Simone Weil decide deixar a educação para "mergulhar na condição de oprimida" (BOSI apud WEIL, 1996, p. 4I) e ter o esperado "contato com a vida real” (WEIL, 1996, p. 83), buscando colocação como operária. É a partir dessas experiências que, nos anos seguintes, irá construir considerações - feitas quase sempre às pressas e em condições precárias - que são, ainda hoje, incrivelmente pertinentes.

\section{UMA VOZDE REFLEXÃO NO CHÃO DAFÁBRICA}

Talvez a mais importante das reflexões de Simone Weil é a de que os operários vivenciam, diariamente, a condição absoluta de escravos. Essa condição não sofre a reviravolta proposta por Hegel na dialética do senhor e do escravo ${ }^{4}$, pois, ao contrário de outras formas de escravidão, pautadas em circunstâncias, na fábrica a servidão "está transportada para o próprio trabalho" (WEIL, 1996, p. I 13), para a própria condição de ser não pensante e não detentor de direitos, em suma, condição de objeto. Narra Simone, em uma linguagem confusa que permeia muitos de seus escritos do período, que:

\footnotetext{
${ }^{4}$ Dialética do senhor e do escravo: Imagem que Hegel utiliza na Fenomenologia do Espírito para explicar o processo de constituição da consciência em interação com a outra consciência. Em sua relação com o que lhe é outro, o sujeito sempre o trata como objeto; no entanto, no caso de outra consciência, temos uma relação entre duas subjetividades. Portanto, a consciência subjetiva sempre procura submeter outra consciência, tratando-a como a um objeto. É este processo que Hegel descreve como relação entre o senhor (Herrschaft) e o escravo (Knechtschaft). Entretanto, o senhor, embora se considere superior, necessita ser reconhecido pelo escravo, seu inferior. $\mathrm{O}$ escravo, por sua vez, pelo seu trabalho, conquista sua autonomia e sua identidade. Assim, as posições terminam por se inverter. (JAPIASSÚ, H., MARCONDES, D. 2006, p. 74).
} 
Saindo do dentista (terça de manhã, eu acho, ou antes, quinta de manhã) e subindo no ônibus, reação estranha. Como que eu, a escrava, posso entrar neste ônibus, usá-lo graças a meus 12 centavos como qualquer um? Que favor extraordinário! Se me obrigassem brutalmente a descer dele dizendo que meios de locomoção tão cômodos não são para mim, que eu só devo andar a pé, acho que até me pareceria natural. A escravidão me fez perder totalmente o sentimento de ter direitos. Parece-me um favor ter momentos em que não preciso aguentar a brutalidade humana. (WEIL, 1996, p. 105-106)

As demonstrações da facilidade com que conceitos outrora tão sedimentados se perdem na lógica da fábrica são recorrentes nos diversos escritos da filósofa, seja nas cartas reunidas ou em forma de anotações fragmentadas, misturadas aos relatos diários das atividades desempenhadas durante a jornada de trabalho. Pequenas (se é que se pode falar em tal escala) humilhações diárias - muitas delas inúteis, como o caso da grande discrepância entre a temperatura da fábrica e do vestiário que machuca o operário sem qualquer razão racional ou prática (WEIL, 1996, p. 121) - vão sendo apresentadas uma atrás da outra e torna-se quase palpável o verdadeiro colapso da mulher, que admite:

O esgotamento acaba por me fazer esquecer os verdadeiros motivos de minha estada na fábrica, torna quase invencível para mim a tentação mais forte que esta vida inclui: a de não pensar mais, o único meio de não sofrer com ela. Só no sábado de tarde e no domingo é que minhas lembranças voltam - farrapos de ideias! -, que me lembro de que sou também um ser pensante. Pavor que me domina quando constato a dependência em que me acho das circunstâncias exteriores: bastaria que elas me obrigassem um dia a um trabalho sem repouso semanal - o que, afinal de contas, sempre é possível e eu me transformaria numa besta de carga, dócil e resignada.

(WEIL, 1996, p. 96)

Outra consideração de suma importância reside na exata sensação de docilidade não de revolta, como havia imaginado Simone - originada pela condição de operária. Em carta endereçada à Albertine Thévenon, há a síntese desse sentimento:

Quanto a mim mesma, para mim pessoalmente, veja o que significou o trabalho na fábrica. Mostrou que todos os motivos exteriores (que antes julgava interiores) sobre os quais, para mim, se apoiava o sentimento de dignidade, o respeito por mim mesma, em duas ou três semanas ficaram radicalmente arrasados pelo golpe de uma pressão brutal e cotidiana. E não creio que tenha nascido em mim sentimentos de revolta. Não, 
muito ao contrário. Veio o que era a última coisa do mundo que eu esperava de mim: a docilidade. Uma docilidade de besta de carga resignada. Parecia que eu tinha nascido para esperar, para receber, para executar ordens - que nunca tinha feito senão isso - , que nunca mais faria outra coisa. (WEIL, 1996, p. 79)

A impossibilidade de manifestação de revolta aparece, também, com grande frequência, sempre associada à sensação de que o operário está sozinho - igualmente distante de patrões, sindicatos (WEIL, 1996, p. 167) e a própria sociedade (WEIL, I996, p. 156) - e de que qualquer manifestação de discordância trabalha contra sua própria condição:

Impossível a revolta, a não ser por lampejos (quero dizer, mesmo em termos sentimentais). Em primeiro lugar, contra o quê? A gente está sozinho, com seu trabalho, não poderia revoltar-se senão contra ele; ora, trabalhar com essa irritação seria trabalhar mal, e daí morrer de fome. (....) Aqui somos como cavalos que se ferem a si próprios quando puxam os freios - e o jeito é curvar-se. Chega-se até a perder consciência dessa situação, a gente suporta, é tudo. Qualquer despertar do pensamento, torna-se, então, doloroso. (WEIL, 1996, p. 97)

Assim, quando Simone narra a diferença entre a teoria e a prática no aproveitamento das horas de lazer, ensinando que, se "teoricamente, são razoáveis, com a jornada de oito horas; praticamente elas são absorvidas por um cansaço que muitas vezes chega ao embrutecimento" (WEIL, 1996, p. 84), é quase possível ouvir o verso da canção Capitão da Indústria que diz "eu às vezes fico a pensar em outra vida ou lugar, estou cansado demais, eu não tenho tempo de ter o tempo livre de ser, de nada ter que fazer (...) eu acordo pra trabalhar, eu durmo pra trabalhar, eu corro pra trabalhar" (VALLE; VALLE, 1996).

A experiência do trabalho na fábrica leva, ainda, a outra importante reflexão da filósofa: a de que o operário vivencia verdadeira obsessão por centavos. Expõe, para demonstrar seu ponto, situações humilhantes e reiteradas de incertezas quanto ao valor do pagamento, de recebimento de ordens e de constante medo de que qualquer reclamação possa levar ao desemprego e, consequentemente, à fome e à morte.

Cabe aqui um paralelo da obsessão dos centavos, convertida por Simone em uma característica doentia da sociedade burguesa - a monomania da contabilidade (WEIL, 1996, p. 137), que estabelece a ausência de valor para coisas que não possam ser registradas monetariamente - com a brilhante tese apresentada por Zygmunt Bauman em seu segundo capítulo de Modernidade Líquida em que debate a obsessão da sociedade atual em "ir às compras":

$\bigcirc$ que quer que façamos e qualquer que seja o nome que atribuamos à nossa atividade, é como ir às compras (...) Não se 
compra apenas comida, sapatos, automóveis ou itens de mobiliário. A busca ávida e sem fim por novos exemplos aperfeiçoados e por receitas de vida é também uma variedade do comprar (...) Há muitas áreas em que precisamos ser mais competentes, e cada uma delas requer uma "compra". (...) A lista de compras não tem fim. Porém por mais longa que seja a lista, a opção de não ir às compras não figura nela. $\mathrm{E}$ a competência mais necessária em nosso mundo de fins ostensivamente infinitos é a de quem vai às compras hábil e infatigavelmente. (BAUMAN, 200 I, p. 95-96)

Essas circunstâncias constroem a dependência exclusiva do salário e fazem com que o sentimento oriundo do recebimento do ordenado seja o de que "esta ninharia de dinheiro passado pelo guichê é, no fim das contas, uma esmola” (WEIL, I996, p. 122). Nesta lógica, "nunca mais, por causa deles [os centavos], é possível esquecer a sujeição da fábrica (...) porque, quem não pode mais produzir depressa não tem mais direito a viver" (WEIL, 1996, p. 123).

\section{CONCLUSÃO: A PONTE ENTRE O CHÃO DA FÁBRICA E O ENSINO JURÍDICO}

Por fim, ainda que não esgotado o debate, vale salientar que Simone força-nos a outra reflexão. Em um pronunciamento, parcialmente colhido por um ouvinte, em 23 de fevereiro de 1937, explicou de forma simples e clara a um auditório de operários o funcionamento do sistema de gratificações implementado por Taylor:

Há um limite para a jornada de trabalho, não só porque o dia propriamente dito só tem vinte e quatro horas, durante as quais é preciso também achar tempo para comer e dormir, mas também porque, ao fim de um certo número de horas de trabalho, a produção não progride mais. (...) ao passo que esse limite não se atinge aumentando a intensidade.

É uma descoberta sensacional do patronato. (...)É algo que não vem imediatamente à mente, porque a intensidade do trabalho não é mensurável como a duração. (...)

Não há nenhum limite para o aumento da produção em intensidade. Taylor conta com orgulho que conseguiu dobrar e até mesmo triplicar a produção em certas fábricas simplesmente pelo sistema de gratificações, pela vigiância dos operários e pela inexorável despedida dos que não quisessem ou não pudessem acompanhar a cadência. Explica que chegou a encontrar o meio ideal para suprimir a luta de classes, porque seus sistemas se baseiam, num interesse comum do operário e do patrão, tendo ambos mais lucro com esse sistema, e o 
próprio consumidor também fica satisfeito porque os produtos são mais baratos.

(WEIL, 1996, p. |47-|48)

Contudo, o sistema de racionalização (de meritocracia, porque não), pensado pela lógica burguesa do patrão, é falho ao operário, ainda que pretensamente seja válido para todos os participantes do modo de produção, pois o transforma em "molécula":

Esse sistema também reduziu os operários, por assim dizer, ao estado de moléculas, fazendo deles uma espécie de estrutura atômica das fábricas. Trouxe o isolamento dos trabalhadores. É uma das fórmulas essenciais de Taylor, que é preciso dirigir-se ao operário individualmente; considerar nele o indivíduo. O que ele quer dizer é que é preciso destruir a solidariedade operária por meio das gratificações e da concorrência. É isto que produz esta solidão, talvez o caráter mais marcante das fábricas organizadas dentro do atual sistema (...)

A divisão da classe operária, portanto, está na base desse método. $O$ desenvolvimento da concorrência entre os operários é uma parte integrante dele, assim como o apelo aos mais baixos sentimentos. O salário é sua única motivação. Quando o salário não basta, vem a brutal despedida. A cada momento do trabalho, o salário é determinado por uma gratificação. A todo momento, é preciso que o operário calcule para saber quanto ganhou.

(WEIL, 1996, p. 150)

Nesse aspecto, a ideia exposta n'O Capital, de Karl Marx, de que é preciso que a classe de trabalhadores reconheça como natural sua subjugação, mostra-se, na lógica da fábrica vivenciada por Simone Weil, verdadeira e empiricamente comprovada:

Não basta que as condições de trabalho apareçam num polo como capital e no outro como pessoas que não têm nada para vender, a não ser sua força de trabalho. Tampouco basta obrigálas a se venderem voluntariamente. No envolver da produção capitalista desenvolve-se uma classe de trabalhadores que, por educação, tradição e hábito, reconhece as exigências desse modo de produção como leis naturais e evidentes por si mesmas. (MARX, 2013, p. 983)

Contudo, para Simone, o caminho para uma possível solução não passa pela revolução dos trabalhadores tal qual imaginada pelos marxistas. Pelo contrário, a crítica à ditadura do proletariado é contundente:

Este desgosto do trabalho altera nos operários toda a 
concepção de vida, toda a vida. A humilhação degradante que acompanha cada um de seus esforços procura uma compensação numa espécie de imperialismo operário entretida pelas propagandas derivadas do marxismo; se um homem que fabrica porcas e parafusos sentisse, fabricando suas porcas e parafusos, um orgulho legítimo e limitado, não provocaria artificialmente em si mesmo um orgulho ilimitado pelo pensamento de que sua classe está destinada a fazer história e dominar tudo. (WEIL, 1996, p. 174- 175)

A proposta, esclarecida num artigo escrito em 194 I e publicado em 1942, pode ser sintetizada da seguinte forma:

É preciso que o futuro se abra ante o operário com uma certa possibilidade de previsão, a fim de que ele tenha o sentimento de progredir no tempo, de caminhar, a cada esforço, na direção de um acabamento. Atualmente, o esforço que ele está realizando, não o leva a nenhuma parte (...) quanto ao futuro próximo, cada operário deveria, o quanto possível, saber mais ou menos o que terá que fazer durante os oito ou quinze dias que se vão seguir, e mesmo ter direito a uma certa escolha quando à ordem de sucessão das várias tarefas. Em relação ao futuro longínquo, ele deveria ter condições de projetar algumas marcas que lhe determinam o caminho, de uma forma, é claro, menos extensa e menos precisa do que o patrão e o gerente, mas mesmo assim análoga. Assim, sem que seus direitos efetivos tenham sido de alguma forma acrescentados, ele participará desse sentimento de enraizamento de que o coração do homem tem sede, e que, sem diminuir a dor, suprime o desgosto. (WEIL, 1996, p. 173)

Consciente de que sua proposta - ousada por não apresentar alteração fundamental na lógica da fábrica ao mesmo tempo em que propõe exatamente isso, por mais contraditório que tal argumento pareça - é de difícil aplicação, prossegue:

Os principais obstáculos estão nas almas. É difícil vencer o medo e o desprezo. Os operários, ou, pelo menos, muitos deles adquiriram, depois de mil feridas, uma amargura quase incurável que faz com que eles comecem a olhar como uma cilada tudo o que lhes vem de cima, sobretudo dos patrões (...) Muitos patrões temem que uma tentativa de reforma, seja qual for, por mais inofensiva que seja, traga novos recursos aos cabeças, aos quais atribuem todos os males, sem exceção, existentes no campo social (...) De resto, o esforço a realizar não recai só sobre os patrões e os operários, mas sobre toda a 
sociedade; especialmente a escola deveria ser imaginada de uma forma totalmente nova, para formar homens capazes de compreender o conjunto do trabalho do qual participam. Não que o nível dos estudos teóricos deva ser rebaixado; antes, trata-se do contrário; deveríamos fazer muito mais para despertar a inteligência: e, ao mesmo tempo, o ensino deveria tornar-se muito mais concreto. (WEIL, 1996, p. 174)

Conclui afirmando que as mazelas originadas lá na fábrica devem ser corrigidas e arremata que, para que isso ocorra, "seria preciso primeiro que os especialistas, engenheiros e outros tomassem mesmo a peito não só construir objetos, bem como não destruir homens" (WEIL, 1996, p. 175).

Sem dúvidas a proposta da filósofa é utópica, fantasiosa, quer situada no contexto histórico de guerra e miséria em que foi escrita, quer num contexto atual. Contudo, em momentos de utopia ${ }^{5}$ se faz necessária a distinção entre as formas de utilização do conhecimento. "Penso que a cultura intelectual, escreve Simone a Thibon, longe de dar direito a privilégios, é, em si mesma, um privilégio quase terrível que exige, em contrapartida, responsabilidades terríveis" (BOSI apud WEIL, 1996, p. 6I), escreveu Simone, demonstrando sua sensibilidade ímpar à questão.

Mesma sensibilidade que se pode perceber no discurso de Jessé Souza, que defende, em sua brilhante obra A Tolice da Inteligência Brasileira, que:

Normalmente a linguagem técnica dos especialistas só serve para criar um abismo entre estes e leigos, para proteger e "distinguir" o especialista dentro da linguagem hermética para iniciados e permitir o uso do conhecimento como mero "fetiche" do mesmo modo que se utiliza o dinheiro na vida social: para "comprar" reconhecimento e legitimar privilégios.

(SOUZA, 2015, p. 13)

É dentro dessa reflexão que se podem tangenciar os pensamentos de Simone Weil e a Escola da Ponte, que surgiu do desejo de criar uma instituição que se diferenciasse do modelo tradicional. Por isso, a escola idealizada por José Pacheco, além de não possuir séries, testes, turmas ou aulas, também se diferencia pela forma de aprendizagem: por um lado os professores não se prendem a uma única turma ou disciplina; por outro, os

${ }^{5}$ Utopia (...) 2. Em um sentido mais amplo, designa todo projeto de uma sociedade ideal perfeita. O termo adquire um sentido pejorativo ao se considerar esse ideal como irrealizável e portanto fantasioso. Por outro lado, possui um sentido positivo quando se defende que esse ideal contém o germe do progresso social e da transformação da sociedade. JAPIASSÚ, Hilton e MARCONDES, Danilo. Op. Cit. Página 274. 
alunos, geralmente considerados crianças ou adolescentes problemáticos, desenvolvem tanto estudos individuais, que são mais tarde compartilhados com os demais colegas, quanto projetos de pesquisa, que são feitos em grupos formados de acordo com suas áreas de interesse (PACHECO, 201 I).

Em sentido contrário, a proposta das escolas de Direito desde sua fundação, como bem observam Lilia Moritz Schwarcz (SCHWARCZ, 2008, p. 14I-238) e Ricardo Marcelo Fonseca (FONSECA, 2008, p. 270-293), pouco parece ter mudado desde a criação das Faculdades de Recife e São Paulo, em 1827.

A despeito de algumas alterações e atualizações, as faculdades de Direito ainda parecem primar pela construção, no mesmo estudante, de dois tipos de jurista, o que pode fazer com que o ensino jurídico seja contraditório e conflituoso. Busca-se o jurista eloquente, "aquele que tipicamente é um tribuno, é alguém que transmite com eficácia e grandiloquência seu saber por meio do discurso declamado" (FONSECA, 2008, p. 280), e o cientista, que "vai de modo crescente constituindo revistas acadêmicas, o jurista que passa a valorizar, como fundamento legitimador de seu discurso, não mais as estratégicas retóricas, mas a solidez dos argumentos científicos" (FONSECA, 2008, p. 282).

Assim, nesse ambiente formativo de conflito, é importante dotar a pesquisa acadêmica de mais responsabilidade nos cursos de Direito. A pesquisa é, sim, tarefa de grande responsabilidade e, por tal razão, deve ser desenvolvida com ética e honestidade. Nesse sentido, o alerta de Miriam Halpern Pereira é suficiente para demonstrar a necessidade da ética e da seriedade na pesquisa científica. Argumenta, de forma brilhante e cristalina, a historiadora portuguesa que

É essencial sublinhar que a investigação científica neste domínio é que permite abancar no conhecimento do passado. Esse conhecimento não é um facto adquirido. (...) É necessário salientar que compreender o passado é resultado de um processo difícil e que o seu conhecimento resulta do progresso da investigação científica. Como noutros domínios, o conhecimento não é algo adquirido para sempre, carece pelo contrário de permanente atualização.

O progresso no conhecimento do passado, apesar de ser um tempo acabado, é evidente para os especialistas, mas não para a comunidade académica em geral ou para o grande público.

(PEREIRA, 2015, p. 217)

Essa ideia, ainda que descrita para a pesquisa histórica, pode ser adequadamente transposta para o ensino jurídico. Prossegue Pereira, alertando que a transferência do conhecimento da academia para a sociedade - o que defende como função essencial da universidade - sofre, atualmente, grande defasagem. Para a historiadora, o ambiente universitário fecha-se em si mesmo, transformando ações de contato com os demais espaços sociais em eventos esporádicos e limitados (PEREIRA, 2015, p. 218-219) e, 
para remediar o perigoso afastamento, Pereira propõe nova equação da relação entre a academia e a sociedade, para "encontrar formas regulares de manter a comunicação de qualidade entre a Universidade e a sociedade no âmbito da História" (PEREIRA, 20 I 5, p. 228).

Nesse sentido, esclarecedora é a conclusão de António José Avelãs Nunes:

\begin{abstract}
Aos universitários e aos intelectuais em geral cabe, como cidadãos, como universitários e como intelectuais, uma responsabilidade enorme nas lutas a travar, tanto no que se refere ao trabalho teórico (que nos ajuda a compreender a realidade) como no que respeita à luta ideológica (que nos ajuda a combater os interesses estabelecidos e as ideias feitas), porque a luta ideológica é, hoje mais do que nunca, um fator essencial da luta política e da luta social (da luta de classes).

(NUNES, 20।2, p. |85-186)
\end{abstract}

Assim, diante de um panorama que não propõe uma ruptura tal qual aquela prevista por Marx, mas sim uma construção de uma nova forma de educar para sedimentar transformação efetiva, é possível sugerir iniciativas educacionais no ensino jurídico quem sabe como as propostas pela Escola da Ponte em Portugal readequadas para o ambiente universitário - como motor capaz de guiar algo que, por falta de melhor nomenclatura, se pode chamar de revolução.

\title{
REFERÊNCIAS
}

BAUMAN, Zygmunt. Modernidade Líquida. Rio de Janeiro: Zahar, 2001 .

FONSECA, Ricardo Marcelo. Vias da modernização jurídica brasileira: a cultura jurídica e os perfis de juristas brasileiros do século XIX. Revista brasileira de estudos políticos [RBEP]. Belo Horizonte. Número 98. Julho-Dezembro 2008. Disponível em: <http://www.pos.direito.ufmg.br/rbep/index.php/rbep/article/view/76>. Acesso em 8 set. 2017.

HOBSBAWM, Eric. A Era dos Extremos: o Breve Século XX(|9|4 - |99|). 2. ed. São Paulo: Companhia das Letras, 1995.

JAPIASSÚ, Hilton e MARCONDES, Danilo. Dicionário Básico de Filosofia. 4. ed. Rio de Janeiro: Jorge Zahar Editora, 2006.

MARX, Karl. O Capital: Crítica da Economia Política - Livro I: O Processo de Produção do Capital. Editora Boitempo, 2013. 
NUNES, António José Avelãs. A crise atual do capitalismo: capital financeiro, neoliberalismo, globalização. São Paulo: Editora Revista dos Tribunais, 2012.

PACHECO, José. Escola da Ponte: formação e transformação da educação. 4. ed. Petrópolis: Vozes, 20 I I.

PEREIRA, Miriam Halpern. O lugar da História nas relações entre a Universidade e a sociedade. Práticas da História, Journal on Theory, Historiography and Uses of the Past I, $n^{\circ}|(20 \mid 5): 2| 5-230$. D is ponível e m : < http://www.praticasdahistoria.pt/pt/numeros/praticas-da-historia- I - I-20 I 5/o -lugarda-historia-nas-relacoes-entre-a-universidade-e-a-sociedade/>. Acesso em 15 set. 2017.

SCHWARCZ, Lilia Moritz. O Espetáculo das Raças: cientistas, instituições e questão racial no Brasil ( 1870- 1930). São Paulo: Companhia das Letras, 2008.

SOUZA, Jessé. A tolice da inteligência brasileira: ou como o país se deixa manipular pela elite. São Paulo: Leya, 2015.

VEYNE, Paul Marie. Como se escreve a história: Foucault revoluciona a história. 4. ed. Brasília: Universidade de Brasília, 1998.

WEIL, Simone. A Condição Operária e Outros Estudos sobre a Opressão. 2. ed. Rio de Janeiro: Paz e Terra, 1996.

TITANIC (Titanic). Direção: James Cameron. Produção: James Cameron e Jon Landau. Elenco: Leonardo DiCaprio, Kate Winslet e outros. Twentieth Century Fox Film Corporation, Paramount Pictures, Lightstorm Entertainment, 1997. DVD (I94 minutos).

VALLE, Marcos e VALLE, Paulo Serio. "Capitão de Indústria". In: Nove Luas. OS PARALAMAS DOSUCESSO. Gravadora EMI, 1996. CD.

Recebido em: 24/10/2017

Aprovado em: 13/1 1/2017 
